American J. of Engineering and Applied Sciences 3 (4): 597-603, 2010

ISSN 1941-7020

(C) 2010 Science Publications

\title{
Elapse Time Factor on Induced Vegetative Moisture Uptake in an Unsaturated Soil
}

\author{
Muazu Mohammed Abdullahi, Nazri Bn Ali and Kamarudin Bn Haj Ahmed \\ Department of Geotechnics and Transportation, Faculty of Civil Engineering, \\ University Technology Malaysia, 81310 UTM Skudai, Johor Bahru, Johor, Malaysia
}

\begin{abstract}
Problem statement: Soil consolidation is generally time dependent, therefore soil displacement as a result root water uptake is space and time dependent. The time-dependent nature of abstraction of ground water by vegetation need to be evaluated in order understand the effect of time elapse on matric suction a generation and subsequent ground displacement. Approach: The current approach used the theory of unsaturated soils with modification due to assumption made in the course of model formulation with two stress state variables principles. A volume change was modeled as a result of matric suction change caused by vegetative induced moisture migration. The effect of elapsed time for full cycle are simulated for periods that covers a spring/summer soil-drying phase of 6 months followed by an autumn/winter 6 month recharge phase. Results: The results of this evaluation showed that the soil matric suction and deformation increases with time spring/summer soil-drying phase of 6 months followed decreases during autumn/winter 6 month recharge phase. There is also decreased in the suction generation and ground displacement as the lateral distance from the Lime tree trunk increases. Conclusion: This study provided a valuable and a relatively accurate means to estimate the influences of vegetation on ground taking the various elapsed times into account. The effect of rainfall has been incorporated into the simulation study, as study of this kind is not complete with inclusion of rainfall data.
\end{abstract}

Key words: Unsaturated soils, matric suction, water-uptake, simulation, deformation, elapse time

\section{INTRODUCTION}

In groundwater field, the soil deformation is studied due to extraction of groundwater. In prediction of soil movement two fundamental stages are generally involved; an assessment of the changes in moisture conditions and the knowledge of the volumatric strains induced by these change. The variation in the moisture content leads to a change in the effective stress that causes a decrease in porosity and void volume which eventually results into volume change in soil. Vegetative induced moisture movement and its subsequent migration to or from atmosphere cause a great deal of soil movement via shrinkage and swelling which causes volume change. This volume change in unsaturated soil can be expressed in terms of deformations or relative movement of the phases of the soils.

The mechanical parameters of the soil were included in the water flow analysis and have been simulated. Infect, soil suction is a limiting factor for root water uptake and a horizontal and vertical distribution of roots determines the dispersal of root water uptake, which must be included in the analysis. Navarro et al. (2009) presented a numerical solver to estimate movement resulting from strain caused by tree activities in urban areas, avoiding high level details characteristics in unsaturated mechanics, which is beyond the scope of building technology for low-rise building according to the author, which should not be an issue to avoid high level details characteristics in unsaturated mechanics especially rainfall data. Fatahi et al. (2009) postulated that the rate of potential transpiration increases the soil matric suction and ground settlement with no clear inclusion of rainfall data. Abstraction of ground water by roots is a complex process involving the interaction of the atmosphere, plant and soil properties Nyambayo and Potts (2010).

A seasonal water variation as a result of root wateruptake was measured by Biddle (1998). A simple concept of sink term for uptake developed by Rees and Ali (2006) is partial coupled to estimate the deformation as a result of vegetative induced matric

Corresponding Author: Muazu Mohammed Abdullahi, Department of Geotechnics and Transportation,

Faculty of Civil Engineering, University Technology Malaysia, 81310 UTM Skudai, Johor Bahru, Johor, Malaysia 
suction changes in this study, incorporating the elapse time with flux boundary condition in the analysis.

Theoretical formulation: According to Fredlund and Hung (2001) stated that the volume change constitutive relations for the unsaturated soils are formulated using the two stress state variables namely; net normal stress and matric suction, thus:

$$
\sigma^{\prime}=\sigma-u_{a}-\chi\left(u_{a}-u_{w}\right)
$$

Where:

$\chi=$ The effective stress parameter which depends on degree of saturation and it is unity when degree of saturation is $100 \%$ and zero when completely dry

$\left(\mathrm{u}_{\mathrm{a}}-\mathrm{u}_{\mathrm{w}}\right)=$ The matrix suction

$\left(\sigma-u_{\mathrm{a}}\right)=$ The net mean stress

$\sigma=$ The effective stress

$\sigma \quad=$ The total effective stress

$\mathrm{u}_{\mathrm{w}} \quad=$ The effective pore water pressure

$\mathrm{S}_{\mathrm{r}} \quad=$ The degree of saturation as is related to the moisture content in the unsaturated soil and porosity

The continuity principal applied to the flow in two directions in a referential element yields the two-dimensional axi-symmatric domain:

$$
\left(\frac{\mathrm{V}_{\mathrm{r}}}{\mathrm{r}}+\frac{\partial \mathrm{V}_{\mathrm{r}}}{\partial \mathrm{r}}+\frac{\partial \mathrm{V}_{\mathrm{z}}}{\partial \mathrm{z}}\right) \mathrm{V}_{\mathrm{T}}=\frac{\partial \mathrm{V}_{\mathrm{w}}}{\partial \mathrm{t}}
$$

Where:

$\mathrm{V}_{\mathrm{T}}=$ Total volume of soil

$\mathrm{V}_{\mathrm{w}}=$ The volume of water in the soil pores

For a constant volume $\mathrm{V}_{\mathrm{T}}$ and expressing Eq. 2 employing Darcy's Law expressed for flow in an unsaturated soils. The total potential for the moisture flow taken as the sum of the pressure or capillary potential and the gravitational potential, follows:

$$
\begin{aligned}
\frac{\partial \theta}{\partial \psi} \cdot \frac{\partial \psi}{\partial \mathrm{t}} & =\frac{\partial}{\partial \mathrm{r}}\left(\mathrm{k}_{\mathrm{w}}^{\mathrm{r}} \frac{\partial}{\partial \mathrm{r}}\left(\frac{\mathrm{u}_{\mathrm{w}}}{\rho_{\mathrm{w}} \mathrm{g}}+\mathrm{Z}\right)\right) \\
& +\frac{1}{\mathrm{r}} \mathrm{k}_{\mathrm{w}}^{\mathrm{r}} \frac{\partial}{\partial \mathrm{r}}\left(\frac{\mathrm{u}_{\mathrm{w}}}{\rho_{\mathrm{w}} \mathrm{g}}+\mathrm{Z}\right) \\
& +\frac{\partial}{\partial \mathrm{z}}\left(\mathrm{k}_{\mathrm{w}}^{\mathrm{z}} \frac{\partial}{\partial \mathrm{z}}\left(\frac{\mathrm{u}_{\mathrm{w}}}{\rho_{\mathrm{w}} \mathrm{g}}+\mathrm{Z}\right)\right)-\mathrm{S}(\mathrm{r}, \mathrm{z})
\end{aligned}
$$

Where:

$\mathrm{k}=$ The unsaturated hydraulic conductivity

$\mathrm{t}=$ The time

$\mathrm{x}, \mathrm{z}=$ The Cartesian coordinate $\theta=$ The volumatric moisture content

$\psi \quad=$ The capillary potential

$\mathrm{r} \quad=$ The radial coordinate

$\mathrm{S}(\mathrm{r}, \mathrm{z})=$ The root water extraction function and $\mathrm{r}$ is the radial coordinate

The root water-uptake extraction function is the sink term $S(\psi, z, r)$ in the Eq. 3 , is given by the equation for water-uptake for two-dimensional axi-symmatric is Rees and Ali (2006):

$\mathrm{S}(\psi, \mathrm{z}, \mathrm{r})=\frac{4 \mathrm{~T}}{\mathrm{z}_{\mathrm{r}} \mathrm{r}_{\mathrm{r}}} \alpha(\psi)\left[1-\frac{\mathrm{z}}{\mathrm{z}_{\mathrm{r}}}\right]\left[1-\frac{\mathrm{r}}{\mathrm{r}_{\mathrm{r}}}\right]$

Where:

$\mathrm{r}_{\mathrm{r}}=$ The maximum rooting depth in the radial direction

$\mathrm{z}_{\mathrm{r}}=$ Maximum rooting depth

$\mathrm{r}=$ The radial distance from the origin of the plant trunk

$\mathrm{z}=$ Depth in the soil profile

The numerical solution of Eq. 3 via the finite element spatial discretization procedure and a finitedifference time-stepping scheme particular adopting a Galerkin weighted residual approach which will yield the disctretized matrix form with added deformation component for full detail Rees and Ali (2006):

$\mathrm{K} \underline{\psi}+\mathrm{C} \underline{\psi}+\underline{\mathrm{J}}+\underline{\mathrm{S}}=0$

The parabolic shape functions and eight-node isoperimatric elements are employed Zienkiewicz and Taylor (1989). The time-dependent nature of Eq. 8, is dealt with via a mid-interval backward difference technique, yielding:

$\underline{\mathrm{K}}^{\mathrm{n}+1 / 2} \underline{\Psi}^{\mathrm{n}+1}+\underline{\mathrm{C}}^{\mathrm{n}+1 / 2}\left[\frac{{\underline{\underline{\varphi^{n+1}}}}^{\underline{\psi^{\mathrm{n}}}}}{\Delta \mathrm{t}}\right]+\underline{\mathrm{J}}^{\mathrm{n}+1 / 2}+\underline{\mathrm{S}}^{\mathrm{n}+1 / 2}=0$

The capillary potential $(\psi)$ was estimated from Eq. 3 , which was used as an input for the stress-deformation analysis.

The elasticity parameters are functions of the stress state of the soil, net normal stress and the matric suction. The elasticity parameters could be estimated using equation from Fredlund and Hung (2001), they were coded into FORTRAN code.

While the soil is normally consolidated clay with a consolidation behavior that can be described by: 


$$
d e=C_{c} \ln \left(\frac{\sigma_{v}+\Delta \sigma_{v}-u_{w f}}{\left(\sigma_{v}-u_{a}\right)+\left(u_{a}-u_{w}\right)_{e}}\right)
$$

Where:

de $=$ The change of void ratio in the element

$\mathrm{C}_{\mathrm{c}}=$ The compression index, is the swelling/shrinkage deformation

Cs $\quad=$ The swelling index

$\sigma_{\mathrm{v}} \quad=$ The vertical total stress

$\Delta \sigma_{\mathrm{v}} \quad=$ The change in the total vertical stresses

$\mathrm{u}_{\mathrm{wf}} \quad=$ The final pore water pressure

$\left(\mathrm{u}_{\mathrm{a}}-\mathrm{u}_{\mathrm{w}}\right)_{\mathrm{e}}=$ The matric suction equivalent Fredlund and Hung (1993)

The boundary condition for the stress-deformation analysis involved having the soil free to move in the vertical direction and fixed in horizontal direction at the left and right sides of the domain and the lower boundary would be fixed in both directions.

\section{MATERIALS AND METHODS}

The mesh consists of 8-noded isoperimatric linear strain quadrilateral elements with 8-displacement and 8pore pressure nodes placed at the corners of each element. The entire finite element mesh consists of 1281 nodes and 400 elements; The axi-symmatric domain is shown in Fig. 1. The mesh was configured to

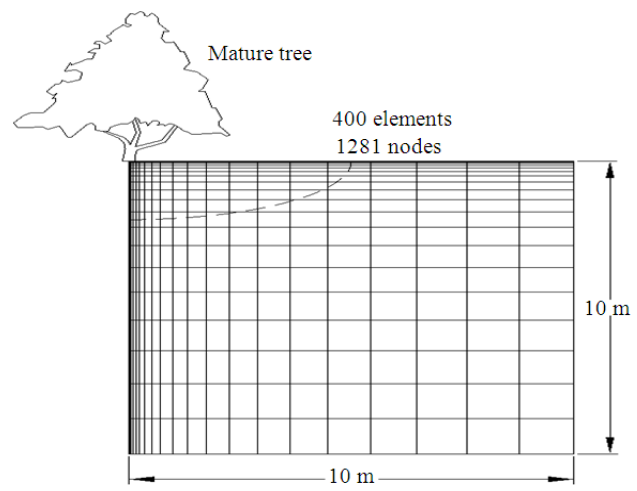

Fig. 1: Axi-symmatric domain

Table 1: Parameters used in the analysis

\begin{tabular}{lll}
\hline Parameters & Values & Reference \\
\hline $\mathrm{k}_{\mathrm{s}}$ & $10^{-6} \mathrm{~m} \mathrm{sec}$ & Biddle $(1998)$ \\
$\mathrm{T}_{\mathrm{p}}$ & $5 \mathrm{~mm} \mathrm{day}$ & Biddle $(1998)$ \\
$\Psi_{\mathrm{d}}$ & $1500 \mathrm{kPa}$ & Fatahi et al. $(2009)$ \\
$\gamma$ & $21 \mathrm{kNm}^{-3}$ & Indraratna et al. $(2006)$ \\
$\mathrm{e}_{0}$ & 0.60 & Powrie et al. (1992) \\
$\mathrm{C}_{\mathrm{c}}$ & 0.13 & Indraratna et al. $(2006)$ \\
$\mu$ & 0.30 & Indraratna et al. $(2006)$ \\
$\theta_{\mathrm{r}}$ & 0.1 & Fredlund and Hung $(2001)$ \\
$\theta_{\mathrm{s}}$ & 0.4 & Fredlund and Hung $(2001)$ \\
$\alpha$ & 0.560 & Fredlund and Hung $(2001)$ \\
$\mathrm{m}$ & 0.29 & Fredlund and Hung $(2001)$ \\
$\mathrm{n}$ & 1.4 & Fredlund and Hung $(2001)$ \\
1 & 0.5 & Fredlund and Hung (2001) \\
\hline
\end{tabular}

offer some refinement within the root zone area since this is the region where the most significant moisture content variations were expected to occur. The boundary condition for the stress-deformation analysis in involved having the soil free to move in the vertical direction and fixed in horizontal direction at the left and right sides of the domain and the lower boundary would be fixed in both directions. The simulation employs a time-step size of $21600 \mathrm{sec}$, which was held constant for the entire period considered. A mature Lime tree of $15 \mathrm{~m}$ height on boulder clay was considered for this analysis. The soil parameters are shown in Table 1 which is typical values for Boulder clay.

The required soil moisture retention characteristics and unsaturated hydraulic conductivity would be simulated from the closed form equation developed by Van Genuchten (1980), thus:

$$
\begin{array}{r}
\theta(\psi)=\theta_{\mathrm{r}}+\frac{\left(\theta_{\mathrm{s}}-\theta_{\mathrm{r}}\right)}{\left[1+|\alpha \psi|^{\mathrm{n}}\right]^{\mathrm{m}}} \begin{array}{l}
\psi \geq 0 \\
\psi<0
\end{array} \\
\mathrm{~K}=\mathrm{Ks} \frac{\left[\left(1+|\alpha \psi|^{\mathrm{n}}\right)^{\mathrm{m}}-|\alpha \psi|^{\mathrm{n}-1}\right]^{2}}{\left(1+|\alpha \psi|^{\mathrm{n}}\right)^{\mathrm{m}(1+2)}}
\end{array}
$$

Where:

$$
\begin{aligned}
\theta_{\mathrm{s}} & =\text { Saturated water content } \\
\theta_{\mathrm{r}} & \text { Residual water content } \\
\Psi & \text { Suction head }(\mathrm{cm}) \\
\mathrm{n}, \mathrm{m}, \alpha= & \text { Empirical shape fitting parameters } \\
& \text { estimated by fitting Eq. } 8 \text { and } 9 \text { to the } \\
& \text { experimental data } \\
\mathrm{K} \text { and } \mathrm{K}_{\mathrm{s}}= & \text { Unsaturated hydraulic conductivity and } \\
& \text { saturated hydraulic conductivity } \\
& \text { respectively while } 1 \text { is a soil specific } \\
& \text { parameter generally assumed to be } 0.5
\end{aligned}
$$

Model verification: The numerical results seem to agree with Fredlund and Hung (2001) analysis Ali and Abdullahi (2010). The slight disparity between the results is two entirely different unsaturated soil models are used in his study. These are the stress state variable for unsaturated soil with Bishop's effective stress theory for the unsaturated coded using FORTRAN and Fredlund and Hung (2001) strictly stress state variable for unsaturated soils. The two different theories influence the volume of change of an unsaturated soil differently. This verification exercise confirms that if the relevant parameters are known, then the current finite element model can predict the matric suction generated and the ground deformation caused by 
vegetative induced moisture movement. The water uptakes are validated with Biddle (1998) and Rees and Ali (2006).

\section{RESULTS}

Figure 2-12 shows the variation of final matric suction for various lateral distance away from the tree trunk for elapse times in days of 30, 190, 270, 360 and 475 days.

Figure 3-13 shows the variation of ground displacement for various lateral distance away from the tree trunk for elapse times in days of 30, 190, 270, 360 and 475 days.

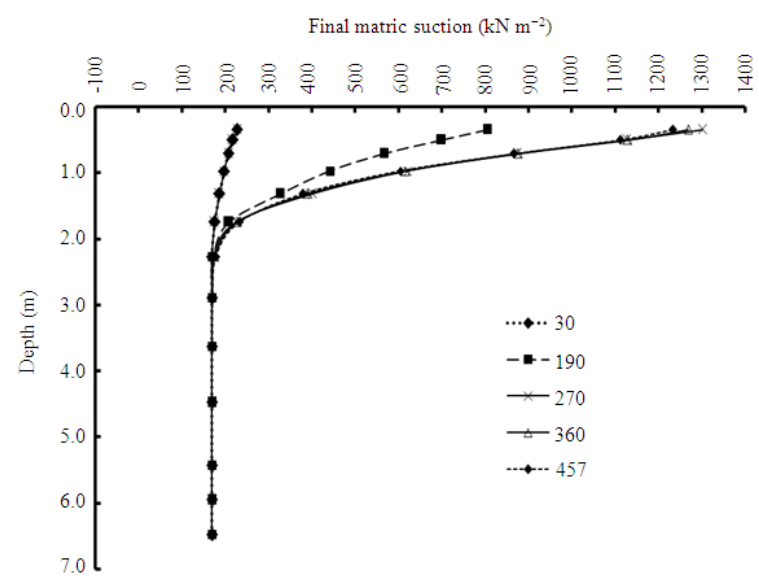

Fig. 2: Variations of matric suction with depth at various elapse times in days at the lime tree trunk

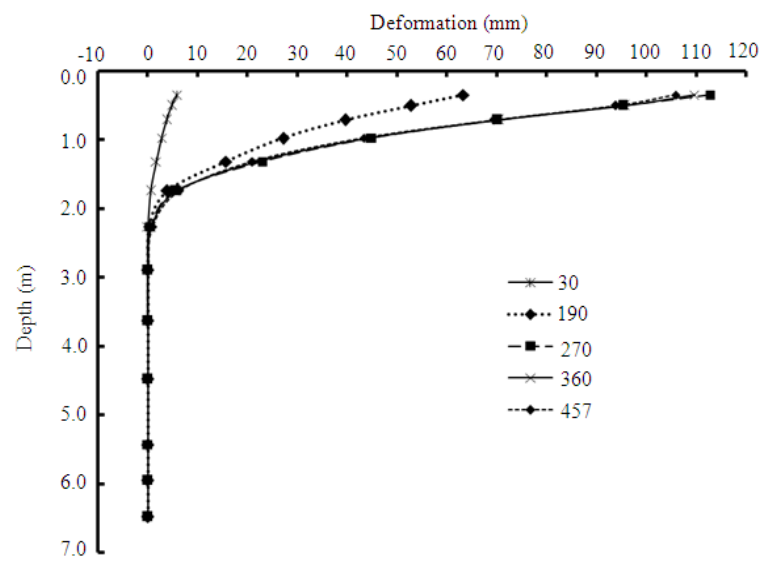

Fig. 3: Variation of ground settlement with depth at various elapse times in days near the trunk of lime tree trunk

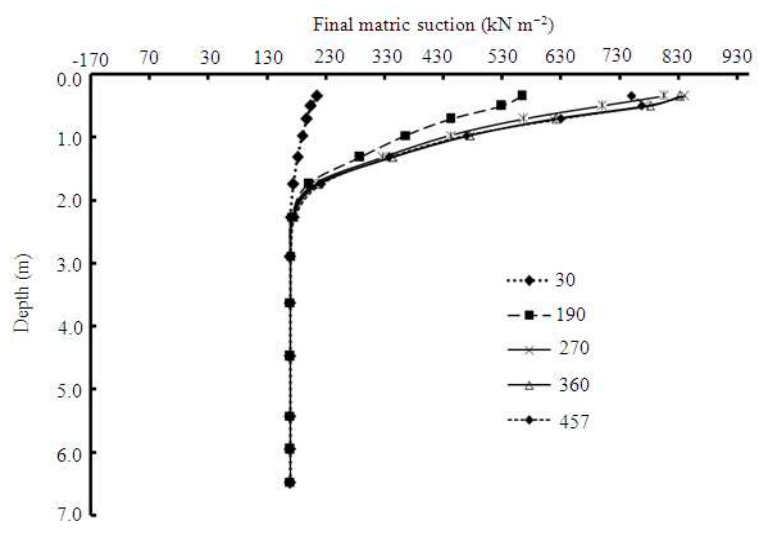

Fig. 4: Variations of matric suction with depth at various elapse times in days at $1.4 \mathrm{~m}$ distance from lime tree

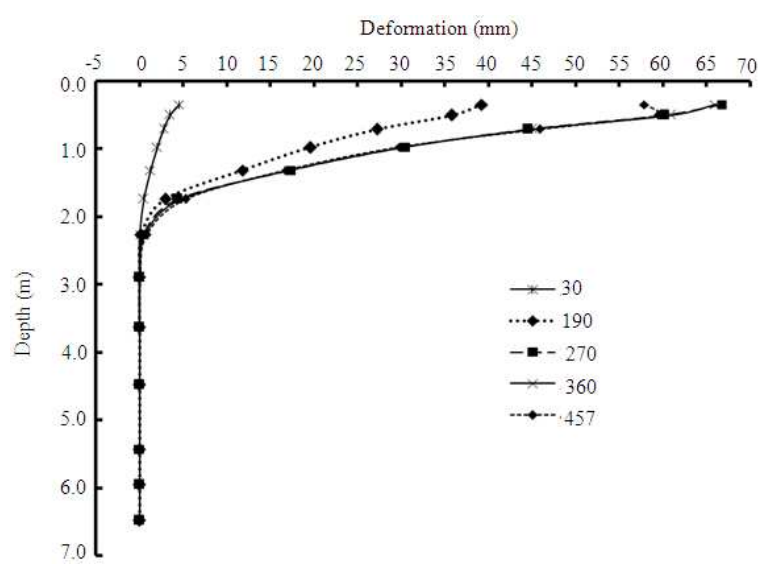

Fig. 5: Variations of ground settlement with depth at various elapse times in days at $1.4 \mathrm{~m}$ distance from lime tree

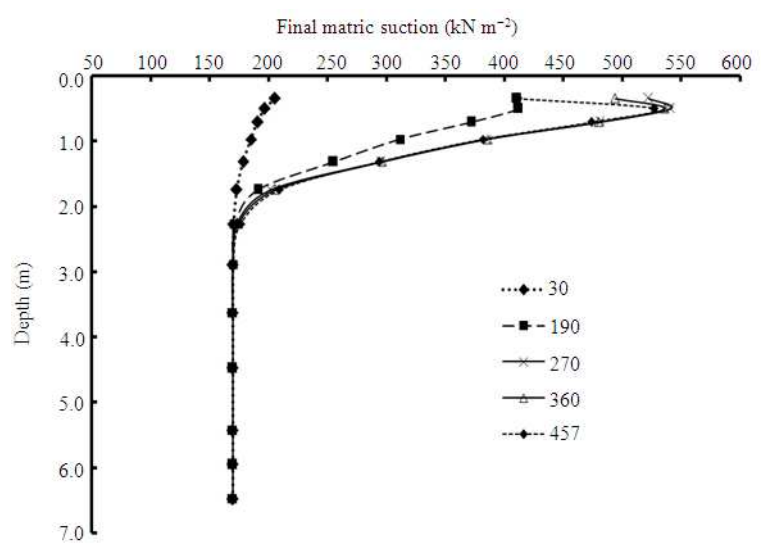

Fig. 6: Variations of matric suction with depth at various elapse times in days at $3.0 \mathrm{~m}$ distance from lime tree 
Am. J. Engg. \& Applied Sci., 3 (4): 597-603, 2010

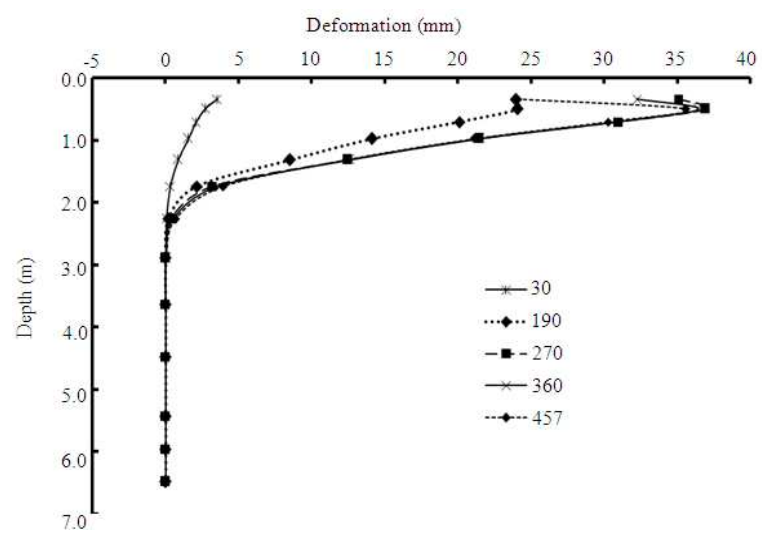

Fig. 7: Variations of ground settlement with depth at various elapse times in days at $3.0 \mathrm{~m}$ distance from lime tree

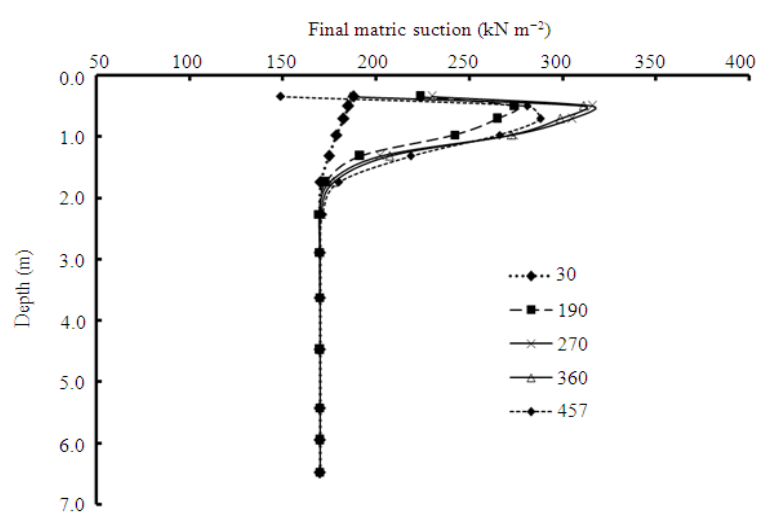

Fig. 8: Variations of matric suction with depth at various elapse times in days at $4.9 \mathrm{~m}$ distance from lime tree

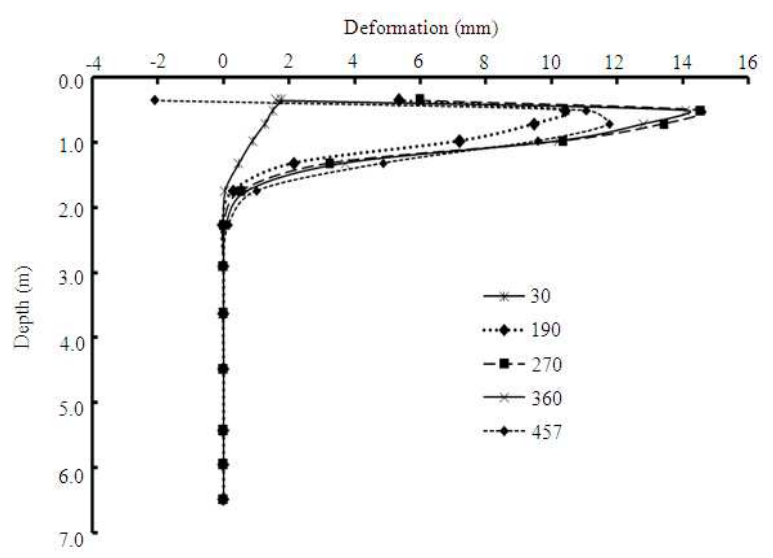

Fig. 9: Variations of ground settlement with depth at various elapse times in days at $4.9 \mathrm{~m}$ distance from lime tree

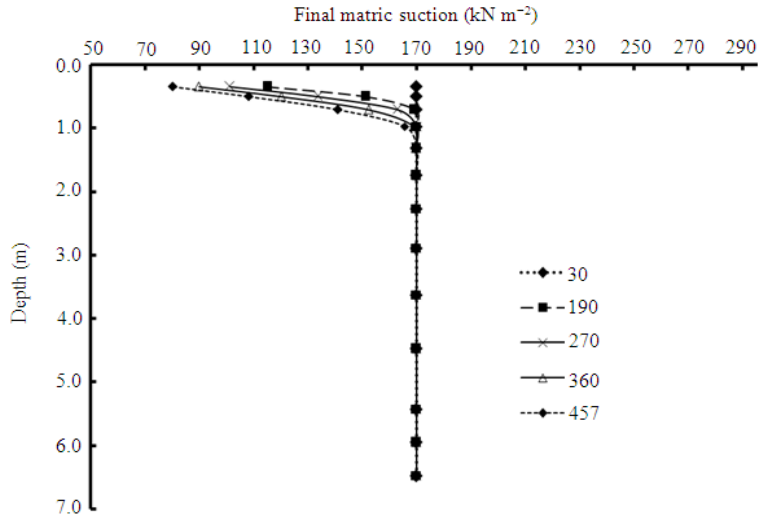

Fig. 10: Variations of matric suction with depth at various elapse times in days at $7.5 \mathrm{~m}$ distance from lime tree

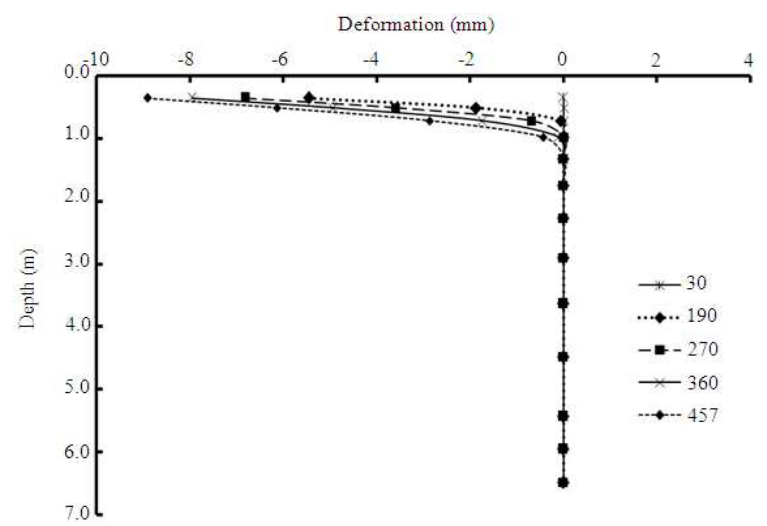

Fig. 11: Variations of ground settlement with depth at various elapse times in days at $7.5 \mathrm{~m}$ distance from lime tree

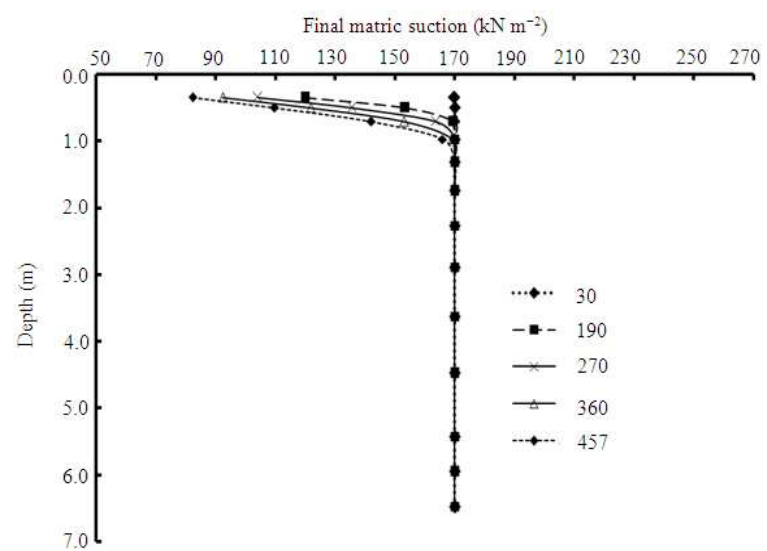

Fig. 12: Variations of matric suction with depth at various elapse times in days at $10.0 \mathrm{~m}$ distance from lime tree 


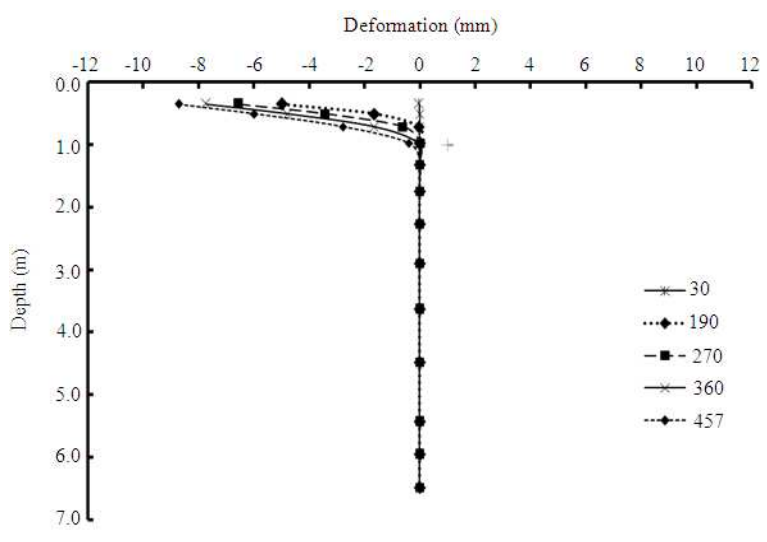

Fig. 13: Variations of ground settlement with depth at various elapse times in days at $7.5 \mathrm{~m}$ distance from lime tree

\section{DISCUSSION}

The magnitude of volume change as a result of vegetative moisture uptake depends much on, not only on the rate of transpiration but also to a greater extends on the soil types and its properties such as degree of compressibility shrinkage and swelling indices. The vegetative induced ground movement might be as a result of vegetative moisture induced migration which causes change in strain resulting from an increased in matric suction. This partly attributed to root water-uptake which causes changes in volume of void and porosity.

The results show decrease in ground movement as the distance from the trunk increases outwards. Fig. 2, $4,6,8,10$ and 12 shows the matric suction changes for different position of Lime tree to a: closer to the tree trunk, at 3.0, 4.9, 7.5 and $10.0 \mathrm{~m}$ away from the tree trunk. The matric suction changes increases as the elapsed time increases especially for the period of Spring/Summer soil drying period phases of six Months as shown in Fig. 4 and 6 which are at the tree trunk and $3.0 \mathrm{~m}$ away. Then deceases during the period of autumn/winter six months recharge.

The graphs tend to behave as if in the autumn/winter six months recharge period, the sink term is deactivated, complete full cycle matric suction is presented. The effect of rainfall was included; rainfall data provided by the Meteorological Office (Bureau of Meteorology, 2006) has been acquired for the nearest weather station to the site (Wolverton Hampshire). Therefore, the deformation simulation also followed almost similar the pattern.

The matric suction decrease as the distance from the trunk mature Lime tree increases and invariable the deformation also decreased as lateral distance increases farther away from the tree. From the data gathered for far the likely safe recommended planting distance from a geotechnical structure taking into consideration the Lime Tree on boulder clay at Stacey Hall Wolverton, England and mechanical properties of boulder clay.

Figure 3, 5, 7, 9, 11 and 13 shows ground movement changes closer to the trunk, at 3.0, 4.9, 7.5 and $10.0 \mathrm{~m}$ away from lime tree trunk. The graphs shows an increases as the elapse time increases especially for the period of spring/summer soil drying period phases of six Months and then decreases during the period of autumn/winter six months recharge period due recharging at that period. The elapse times are 30, 190, 270, 360 and 457 days. The 30 and 190 days the period of spring/summer soil drying period phases of six months while elapse time of 270 and 360 days are the autumn/winter six months recharge period at the time the matric suction decrease and thereby decreasing the deformation due the recharge at that period of the year.

The ground settlement that is induced by the soil consolidation, decreased with depth. The ground settlement is caused by both the root water uptake and the evaporation from the soil surface. The rest of the settlement is assumed to be induced by transpiration. Soil matric suction induced by tree root water uptake propagates radically. The full cycle simulation of matric suction and deformation provides all year round valuable information on how ground movement changes with elapse time with rainfall data incorporated. The analysis shows that the rate of potential transpiration increases the soil matric suction and ground settlement, while the potential transpiration rate has an insignificant effect on the distribution of soil suction. Suction at the wilting point increases the soil matric suction and ground settlement, whereas the saturation permeability decreases the maximum soil matric suction generated. The analysis confirms that the most sensitive parameters, including the transpiration rate, the permeability of the soil and its suction at the wilting point should be measured or estimated accurately for an acceptable prediction of ground conditions in the vicinity of trees.

\section{CONCLUSION}

The matric suction distributions and ground displacement in context of time elapse in the vicinity of vegetation is presented. The effect of rainfall has been incorporated into the simulation study, as study of this kind is not complete with inclusion of rainfall effects. The full cycle simulation of matric suction and deformation provides all year round valuable 
information on how ground movement changes with elapse time using flux boundary condition. The matric suction and ground movement changes with elapse time is an effective tool on decision making as regards to the time dependency of abstraction of ground water by vegetation.

\section{REFERENCES}

Ali, N.B. and M.M. Abdullahi, 2010. Simulation of vegetative induced deformation in an unsaturated soil. Am. J. Environ. Sci., 6: 101-107. http://www.scipub.org/fulltext/ajes/ajes61101-107.pdf

Biddle, G., 1998. Tree Root Damage to Buildings: Pattern of Soil Drying in Proximity to Trees on Clay Soils. 1st Edn., Willowmead Publishing, Wantage, ISBN: 095330860X, pp: 675.

Bureau of Meteorology, 2006. Meteorological rainfall data (1979-1980). United Kingdom Bureau of Meteorology.

Fatahi, B., H. Khabbaz and B. Indraratna, 2009. Parametric studies on bioengineering effects of tree root-based suction on ground behavior. Ecol. Eng., 35: $1415-1426 . \quad$ DOI: 10.1016/J.ecoleng.2009.05.014

Fredlund, D.G. and H. Rihardjo, 1993. Soil Mechanics for Unsaturated Soil. 1st Edn., Wiley-Interscience, New York, ISBN: 047185008X, pp: 544.

Fredlund, D.G. and V.Q. Hung, 2001. Predictive of volume change in an expensive soil as a result of vegetation and environmental changes. Proceeding of the ASCE Conference on Expansive Clay Soils and Vegetative Influence on Shallow Foundations, Oct. 10-13, Geotechnical Special Publication, Houston, Texas, Reston, pp: 24-43.
Indraratna, B., B. Fatahi and H. Khabbaz, 2006. Numerical analysis of matric suction effects of the tree roots. Geotech. Eng., 159: 77-90. http://works.bepress.com/bindraratna/73/

Navarro, V., M. Candel, A. Yustres, J. Sanchez and J. Alonso, 2009. Trees, soil movement and foundation. Comput. Geotech., 36: 810-818. DOI: 10.1016/j.compgeo.2009.01.008

Nyambayo, V.P. and D.M. Potts, 2010. Numerical simulation of evapotranspiration using a root water uptake model. Comput. Geotech., 37: 175-186. DOI: 10.1016/j.compgeo.2009.08.008

Powrie, W., J.N. Davies and A.M. Britto, 1992. A cantilever retaining wall supported by a berm during the temporary work activities. Proceeding of the ICE Conference on Retaining Structures, Robinson College, (RSRC'92), Thomas Telford Service Ltd., Cambridge, London, pp: 418-428. http://www.mycrisp.com/publications/A\%20CAN TILEVER\%20RETAINING\%20WALL\%20SUPP ORTED\%20BY\%20A\%20BERM\%20DURING\% 20TEMPORARY\%20WORKS\%20ACTIVITIES.pdf

Rees, S.W. and N. Ali, 2006. Seasonal water uptake near trees: A numerical and experimental study. Geomech. Geoeng., 1: 129-138. DOI: 10.1080/17486020600823855

Van Genuchten, M.T., 1980. A closed-form equation for predicting the hydraulic conductivity of unsaturated soils. Soil Sci. Soc. Am. J., 44: 892-898. http://www.h2ogeo.upc.es/Docencia/Flujo\%20y\%2 0Transporte\%20Multifase/Lectura_3.pdf

Zienkiewicz, O.C. and R.L. Taylor, 1989. The Finite Element Method. 4th Edn., McGraw-Hill, London, pp: 648. 